
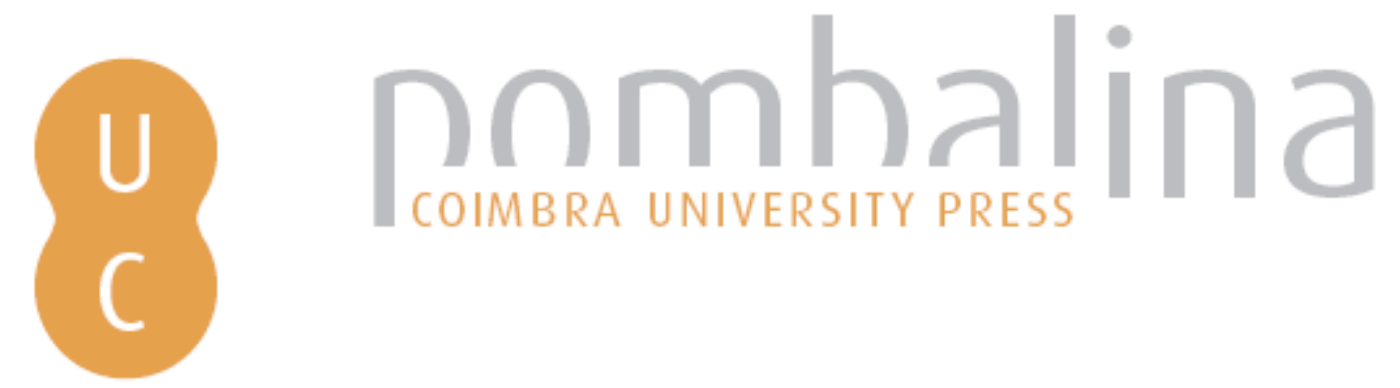

\title{
Estudos de impacte ambiental em infraestruturas rodoviárias com recurso a tecnologia SIG e avaliação multicritério
}

Autor(es): $\quad$ Gonçalves, Agostinho Jordão; Rodrigues, João Coutinho; Sousa, Nuno

Publicado por: Imprensa da Universidade de Coimbra

URL

persistente: URI:http://hdl.handle.net/10316.2/37102

DOI: DOI:http://dx.doi.org/10.14195/978-989-26-0983-6_49

Accessed : $\quad$ 26-Apr-2023 16:05:15

A navegação consulta e descarregamento dos títulos inseridos nas Bibliotecas Digitais UC Digitalis, UC Pombalina e UC Impactum, pressupõem a aceitação plena e sem reservas dos Termos e Condições de Uso destas Bibliotecas Digitais, disponíveis em https://digitalis.uc.pt/pt-pt/termos.

Conforme exposto nos referidos Termos e Condições de Uso, o descarregamento de títulos de acesso restrito requer uma licença válida de autorização devendo o utilizador aceder ao(s) documento(s) a partir de um endereço de IP da instituição detentora da supramencionada licença.

Ao utilizador é apenas permitido o descarregamento para uso pessoal, pelo que o emprego do(s) título(s) descarregado(s) para outro fim, designadamente comercial, carece de autorização do respetivo autor ou editor da obra.

Na medida em que todas as obras da UC Digitalis se encontram protegidas pelo Código do Direito de Autor e Direitos Conexos e demais legislação aplicável, toda a cópia, parcial ou total, deste documento, nos casos em que é legalmente admitida, deverá conter ou fazer-se acompanhar por este aviso.

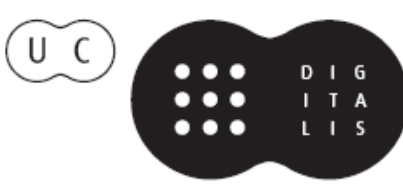




\section{$\forall$ \\ TAS DAS I JORNADAS LUSÓFONAS DE CIÊNCIAS E TECNOLOGIAS DE INFORMAÇÃO GEOGRÁFICA}

Editores

José Gomes dos Santos

Cidália Fonte

Rui Ferreira de Figueiredo

Alberto Cardoso

Gil Gonçalves

José Paulo Almeida

Sara Baptista 


\title{
ARTIGO 49
}

\section{ESTUDOS DE IMPACTE AMBIENTAL EM INFRAESTRUTURAS RODOVIÁRIAS COM RECURSO A TECNOLOGIA Sig e AVALIAÇÃo MULTiCRITÉRIO} GONÇALVES, Agostinho Jordão ${ }^{1}$; COUTINHO -RODRIGUES, João ${ }^{2}$ \& SOUSA, Nuno 3

\begin{abstract}
${ }^{1}$ Instituto de Engenharia de Sistemas e Computadores de Coimbra (INESC Coimbra); Rua Antero de Quental n. ${ }^{\circ}$ 199, 3000 -033 Coimbra, Portugal; Tel: +351 239 851040/9; Fax: +351 239 824692; e -mail: ajordao@dec.uc.pt

2 Departamento de Engenharia Civil da Faculdade de Ciências e Tecnologia da Universidade de Coimbra Instituto de Engenharia de Sistemas e Computadores de Coimbra (INESC -Coimbra) Departamento de Engenharia Civil - FCTUC; Rua Luís Reis Santos - Pólo II, 3030 -788 Coimbra, Portugal

Tel: +351 239 797145; Fax: +351 239 797123; email: coutinho@dec.uc.pt

3 Departamento de Ciências e Tecnologia da Universidade Aberta; Instituto de Engenharia de Sistemas e Computadores (INESC -Coimbra); Delegação de Coimbra da Universidade Aberta; Rua Alexandre Herculano, n. ${ }^{\circ}$ 52, 3000 -019 Coimbra, Portugal; Tel: +351 300 001590; Fax: +351 300 001599; email: nsousa@uab.pt
\end{abstract}

\section{RESUMO}

O Estudo de Impacte Ambiental (EIA) é uma peça fundamental no processo de Avaliação Ambiental a que têm de ser submetidos alguns projetos de engenharia. Este é o resultado de atividades e avaliações metodológicas conducentes a identificar/avaliar possíveis impactes, apresentando medidas de minimização e o plano de monitorização. Se existirem múltiplas alternativas, o EIA deve indicar a "ambientalmente mais favorável". O presente trabalho apresenta uma proposta metodológica para apoio dessas atividades/avaliações, tendo como estrutura integradora um SIG ligado a modelos externos específicos, constituindo -se assim como uma contribuição para o desenvolvimento de um SADE -MC, no domínio ambiental. Essa proposta engloba a conceção duma rotina interativa, em Visual Basic $§$ para suportar os processos de Screening/Scoping, Avaliação da Significância e Seleção dos Indicadores Ambientais. As funcionalidades do SIG, associadas aos módulos externos, são usadas para 
prever/quantificar os impactes e os indicadores ambientais. Estes indicadores são então utilizados como critérios, no módulo de avaliação multicritério que utiliza, nesta aplicação, o método ELECTRE III. Isso permite apresentar uma preordenação final das alternativas, desde a "ambientalmente mais favorável" até à mais adversa. Como caso de estudo, essa proposta metodológica é aplicada a um EIA referente ao projeto de um troço de autoestrada no Centro de Portugal.

\title{
PALAVRAS-CHAVE
}

Estudos de impacte ambiental, Avaliação ambiental em infraestruturas de transporte, Avaliação multicritério, Sistemas de informação geográfica (SIG).

\section{ENVIRONMENTAL IMPACT ASSESSMENT OF ROAD INFRASTRUCTURES USING GIS TECHNOLOGY AND MULTICRITERIA EVALUATION}

\begin{abstract}
The Environmental Impact Study (EIS) is a key formal document in the Portuguese Environmental Assessment context procedure, which is required for an engineering project. This is the outcome of several methodological evaluation assessments and activities undertaken towards the identification of environmental impacts. It should present the mitigation measures and the monitoring plan. If there are several alternatives, the "most -environmental -friendly" should be indicated. This work proposes a methodology to support the Assessment procedure above in a GIS integrating environment. This combination of GIS standard functionalities with the implementation of specific external models constitutes a relevant contribution towards the development of a specific SDSS -MC in the environmental domain. The methodology includes the design of an interactive routine developed in Visual Basic in order to support the Screening/ Scoping, the Significance Evaluation, and Selection of the Environmental Indicators. The GIS functionalities are used to predict impacts and measure related indicators that are used as criteria, within the multicriteria analysis module, based on the ELECTRE III method. This will provide the user with a sorted list of possible alternatives, from the "most -environmental - friendly" down to the least. The methodology was applied to the case study of a motorway in the west -center of Portugal.
\end{abstract}

\section{KEYWORDS}

Environmental impact study, Environmental assessment in transport infrastructure, Multicriteria evaluation, Geographical information system (SIG). 


\section{INTRODUÇÃO}

O Estudo de Impacte Ambiental (EIA) é uma peça fundamental no processo de Avaliação de Impacte Ambiental a que são submetidos alguns projetos ou empreendimentos de engenharia. Essa submissão é função das características do projeto e deve estar de acordo com disposições expressas na legislação. O EIA é o resultado de um conjunto de atividades e avaliações metodológicas conducentes a identificar e avaliar possíveis impactes ambientais, induzidos por essas atividades ou empreendimentos, apresentando as medidas de minimização desses impactes e o plano de monitorização. No caso de existirem múltiplas alternativas em análise, o EIA deve indicar também a alternativa "ambientalmente mais favorável". A natureza eminentemente espacial da informação associada a estes problemas apela ao uso da tecnologia dos Sistemas de informação geográfica (SIG). Dado tratar -se, naturalmente, de um processo de avaliação que envolve em simultâneo diversas dimensões da realidade, as técnicas baseadas em métodos de análise multicritério (MAMC) fornecem uma base metodológica moderna e adequada.

A metodologia que integra SIG e MAMC é aplicada a um caso real: a construção de um novo troço de autoestrada na Região Centro de Portugal, ligando Ílhavo ao Lanço do IC1 - Mira/Aveiro, no seu sublanço Vagos/ Aveiro Sul, denominado SCUT DA COSTA DA PRATA.

\section{APRESENTAÇÃo DO TEMA}

O presente artigo apresenta uma proposta metodológica para apoiar esse conjunto de atividades e avaliações metodológicas, conforme se mostra na Figura 1 abaixo, tendo como estrutura integradora um SIG, apoiado nas suas próprias potencialidades capazes de desempenharem esse conjunto de tarefas, sozinho ou ligado a modelos externos específicos, constituindo -se, assim, como uma contribuição para o desenvolvimento de um futuro sistema de apoio à decisão espacial multicritério (SADE -MC), no domínio ambiental, materializada através da construção e aplicação de um protótipo a um caso real. 
Atas das I Jornadas Lusófonas de Ciências e Tecnologias de Informação Geográfica, Sessão 11, Artigo 49

Estudos de impacte ambiental em infraestruturas rodoviárias com recurso a tecnologia SIG e avaliação multicritério

Agostinho Gonçalves, João Coutinho-Rodrigues \& Nuno Sousa

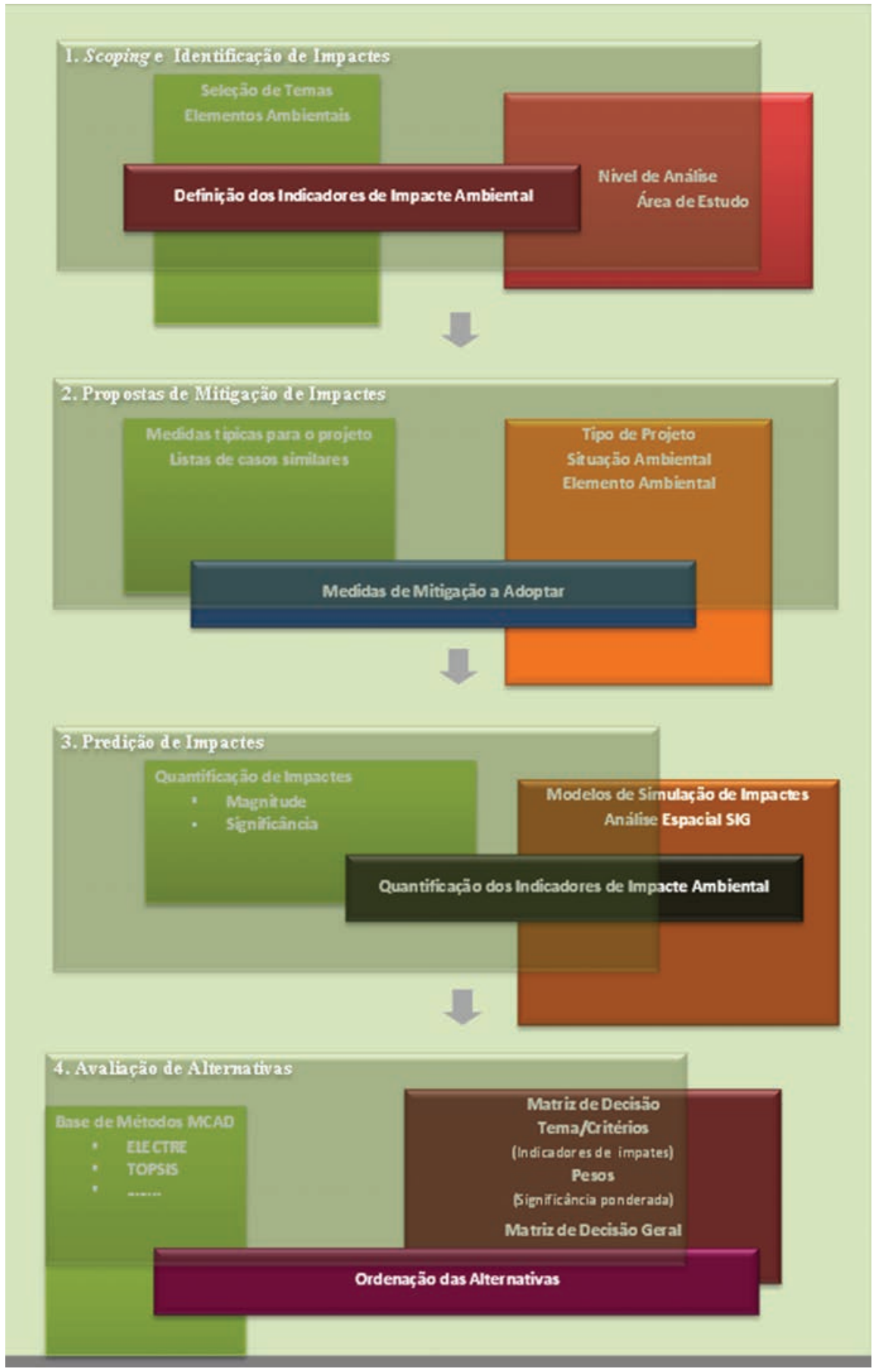

Figura 1 - Fases de aplicação 
Foram desenvolvidas rotinas interativa em Visual Basic ${ }^{\circledR}$ - a linguagem embebida do ArcView ${ }^{\circledR}$ - as quais através de um conjunto de caixas de diálogo e menus, suportam os processos de Screening, Scoping, Avaliação da Significância e Seleção dos Indicadores de Impacte Ambiental. As funcionalidades do SIG, sozinhas ou associadas a módulos externos específicos, são usadas para prever e quantificar os impactes e os respetivos indicadores ambientais. Estes indicadores de impacte são então utilizados como critérios, no módulo de avaliação multicritério materializado numa base de métodos multicritério de apoio à decisão (BMCAD), que disponibiliza, nomeadamente, o método ELECTRE III. Isso permite apresentar uma preordenação final das alternativas, desde a "ambientalmente mais favorável" até à mais adversa. Essa proposta metodológica é aplicada a um caso concreto de construção de uma estrada.

\section{PROposta metodológica}

Nesta proposta, e no protótipo desenvolvido, o SIG surge como uma plataforma integradora para o desenvolvimento de todas as tarefas.

O protótipo, pensado como SADE -MC, é composto por quatro módulos integrados no SIG ArcView®, conforme se mostra na Figura 2 - Interface Gráfico de Comunicação; Módulo de Manuseamento de Base de Dados; Módulo de Análise e Consulta; Geração de Relatórios.

O Interface Gráfico de Comunicação é essencialmente o interface gráfico do utilizador do ArcView ${ }^{\circledR}$, personalizado para conduzir o utilizador através do programa. O Módulo de Manuseamento de Base de Dados faz uso da suas capacidades de manuseamento de base de dados para guardar e manipular dados geográficos da Base de dados Geográficos SIG (GISBASE) e criar, guardar, manipular e atualizar a Base de Conhecimentos (KB) que suporta a rotina interativa. Finalmente, manipula o módulo da BMCAD. A Base de conhecimentos (KB) é uma base de dados no formato dBase ${ }^{\circledR}$ ou Microsoft Access ${ }^{\circledR}$. As tabelas são agrupadas nas seguintes três categorias, consoante o seu conteúdo informativo: ListaEmpreendimentos; Ambiente; e Mitigação. As primeiras contêm informação sobre os diversos tipos de projetos sujeitos a AIA. As segundas contêm informação (tabelas), sobre os temas ambientais (geomorfologia, recursos hídricos, 
ambiente sonoro, solos, atmosfera, sistemas ecológicos, ocupação do solo, aestética, condicionantes e socioeconómiocos) e respetivos elementos ambientais (ex: relevo e topografia, valores geológicos, qualidade e fluxo das água, ruído, erosão, qualidade do ar, flora e fauna, área agrícolas, paisagem, RAN,REN, etc.). As medidas de mitigação estão organizadas em tabelas de medidas de mitigação, por tipo de projeto. Essas tabelas vão alimentar as caixas de diálogo da rotina VBA. A Base de dados Geográficos (GISBASE) é constituída pela informação digital em vários formatos (shapefile, geodatabase, cad, imagens, tabelas, mdt, grid, etc.) das características ambientais da zona do empreendimento. A BMCAD é constituída por um conjunto de métodos multicritério de apoio à decisão (ex. ELECTRE e TOPSIS), permitindo assim estabelecer uma preordenação ou ordenação final das alternativas.

O Módulo de Análise e Consulta é um módulo chave do sistema. É totalmente desenvolvido dentro da "vista" do subsistema do ArcView®. Faculta ferramentas para expor, analisar, selecionar e recuperar a informação da GISBASE da KB e da BMCAD. Permite visualizar, analisar e processar dados. O Módulo de Geração de Relatórios é destinado a expor os resultados da análise e avaliação numa linguagem familiar (gráficos, relatórios, mapas, etc.).

O caso de estudo refere -se ao novo troço de autoestrada que liga Ílhavo ao Lanço do IC1 - Mira/Aveiro, no seu sublanço Vagos/Aveiro Sul, denominado SCUT DA COSTA DA PRATA. O EIA foi elaborado em 2001 pela firma ARQPAIS, Consultores de Arquitetura Paisagista e Ambiente, Lda., sem recurso a qualquer técnica de análise multicritério, ou outra técnica formal de apoio à decisão, e o projeto técnico disponível era o Estudo Prévio. Na Figura 3 apresenta -se a localização e o enquadramento do projeto em estudo, e a implantação dos traçados das soluções em análise sobre a Carta Militar. Estas foram denominadas Solução 7 Base (A1); Alternativa (A2); Alternativa (A3); Alternativa (A4); e Alternativa (A5). As alternativas A1, A2 e A3 constavam no EIA inicial e o seu traçado já constava do projeto técnico de execução da estrada. As alternativas A4 e A5 foram introduzidas neste trabalho como exercício académico, para teste da proposta metodológica aqui apresentada e sua robustez. 


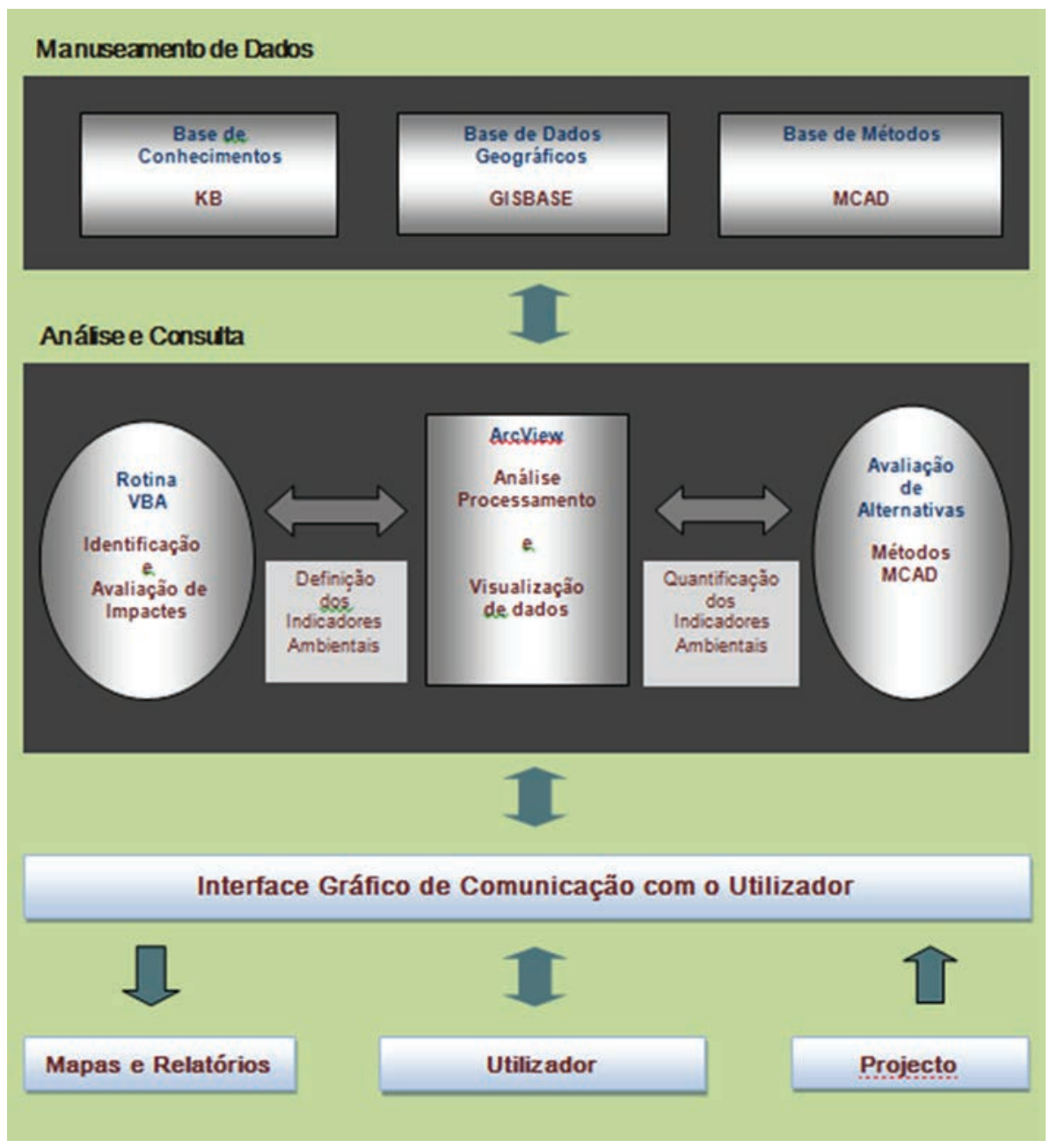

Figura 2 - ArcView ${ }^{\circledR}$ Desktop

\section{Desenvolvimento da metodologia. CASo de ESTUdo}

Uma parte da informação geográfica da área de estudo foi adquirida ao IGeoE - Instituto Geográfico do Exército (altimetria, edifícios, hidrografia, rede viária, mdt - modelo digital do terreno, etc.), e outra recuperada de estudos técnicos relacionados com o EIA do projeto (descritiva, ras- 
ter da Carta Militar, ficheiros dwg com a delimitação espacial de vários aspectos ambientais, nomeadamente geologia, biótipos, condicionantes, etc.). Outra foi ainda recolhida em websites de organismos estatais (ex. SNIG, IA, IEP, SNIRH).
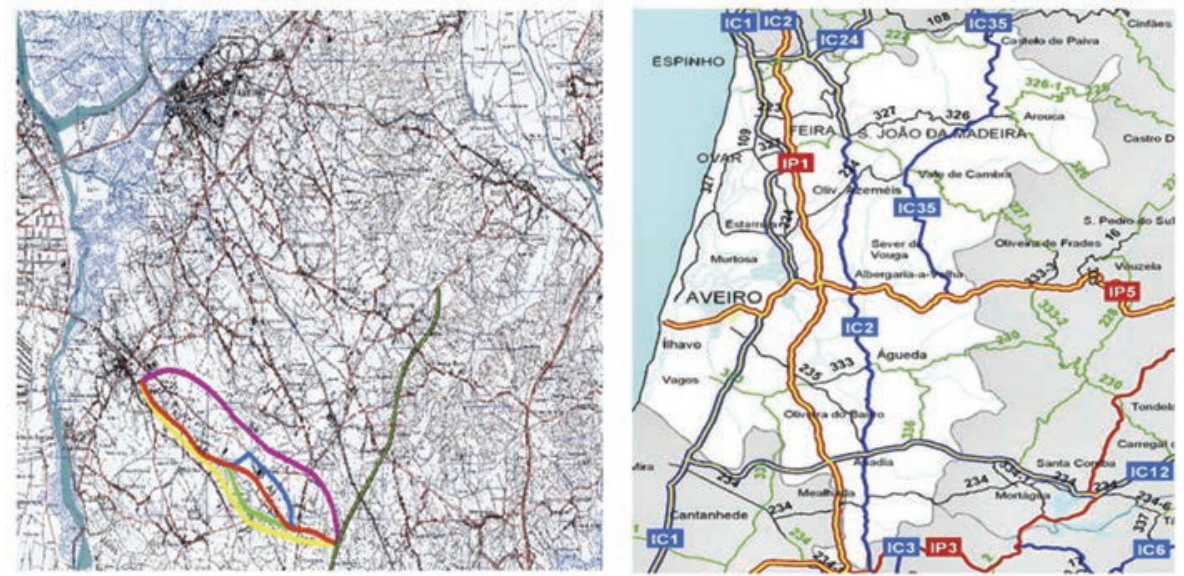

Figura 3 - Localização e implantação das alternativas de traçado

\subsection{Scoping e identificação de impactes}

Na fase de Scoping os elementos suscetíveis de sofrerem impacte devem ser identificados. Para isso, recorreu -se a um dos métodos de identificação existentes, a Matriz de Leopold, (LOOIJEN, 2004). O utilizador, atendendo à situação particular do projeto e das características ambientais da zona em estudo, seleciona os elementos ambientais suscetíveis de sofrerem impacte (ex.: qualidade do ar, fluxo das água superficiais e subterrâneas, etc.). Em termos computacionais, esta fase pode ser executada recorrendo a uma rotina interativa, codificado em Visual Basic for Applications, a linguagem de programação embebida no SIG, ArcView®. Essa rotina conduz o utilizador desde o menu de início do programa, através de um conjunto de caixas de diálogo, até à seleção final dos fatores ambientais suscetíveis de sofrerem impacte. Essa seleção é efetuada pelo utilizador que vai fazendo a "triagem", primeiro do tipo de projeto - num processo de Screening - seguida da fase do empreendimento (construção, funcionamento ou desactivação), depois as ações relacionadas, e finalmente dos elementos ambientais suscetíveis de sofrerem impacte. Assim, a seleção 
dos temas e correspondentes elementos a estudar é feita no final, através de um processo simples de "matching", i.e., 8 para cada ação do projeto selecionada numa ListBox, faz -se corresponder um tema ambiental noutra ListBox e, para cada um destes temas selecionados, faz -se corresponder os elementos ambientais que sofrerão impacte ambiental. Nesta metodologia não interessa a ordem nem se são impactes diretos (ex. ruido, poluição, emprego, ganho de tempo, ocupação de solo agrícola, etc.) ou indiretos (saúde, socioeconómicos, efeito barreia, etc.), assumindo -se que só são selecionados os impactes irreversíveis a longo prazo.

Para cada elemento ambiental que sofra impacte serão escolhidos um ou mais indicadores de impacte ambiental (ex.: área de vegetação afetada pelo empreendimento, ou variação de descritores ambientais, como por exemplo, concentração no ar de NOx, ou concentração de chumbo na água de escorrência da estrada, etc.). Os indicadores ambientais darão assim uma medida do impacte em cada componente (ANTUNES et al., 2001). Para o efeito são utilizados três tipos de indicadores quantitativos e um qualitativo (MOLINES \& CHEVALLIER, 2002): Indicadores Quantitativos, normalmente indicam a área dum elemento ambiental (ex.: vegetação, área agrícolas, etc.) afetado pelo empreendimento. Podem ser de três tipos: Absolutos, Relativos ou Discretos. Estes últimos permitem tomar em conta os elementos pontuais (ex.: passagens, monumentos, poços, etc.). Os Indicadores Qualitativos permitem avaliar os elementos ambientais intangíveis ou não quantificáveis numericamente, como por exemplo a qualidade da paisagem ou a qualidade arquitetónica dum monumento.

Definidos o número e tipo de indicadores por elemento ambiental, teremos o seu número total por tema ambiental. Os indicadores corresponderão aos critérios (atributos), neste caso ambientais, na matriz de decisão usada na Análise Multicritério. O valor desses indicadores será tomado como o desempenho de cada alternativa do empreendimento segundo cada critério. Assim, é nesta fase que vai ser definida a dimensão da matriz de decisão, por tema, e global. Para cada tema ambiental é definida uma matriz de decisão de $m$ linhas ( $m=$ número de alternativas) e $n$ colunas ( $n=$ número de indicadores ambientais para esse tema). Se o tipo de indicador escolhido for Qualitativo, terá de ser realizada uma 
quantificação de atributos qualitativos, por exemplo, numa escala de 1 a 10 (COUTINHO -RODRIGUES, 2003).

\subsection{Desenvolvimento da metodologia.}

A $\boldsymbol{K B}$ dispõe também de uma tabela onde são guardadas as medidas de mitigação para cada tipo de projeto, por tema ambiental, a qual vai sendo enriquecida cada vez que usada e atualizada. A função da seleção destas medidas é, por um lado, propor e atualizar uma base de dados sobre medidas de mitigação e, por outro, elaborar uma ponderação sobre o peso dos critérios ambientais, no que respeita às medidas de mitigação efetivamente a aplicar. É definido um fator de ponderação $\boldsymbol{K}$ através da relação entre o número de medidas de mitigação efetivamente a aplicar por tema ambiental, e o número de medidas previstas na $\boldsymbol{K B}$. Depois na avaliação multicritério por tema, o peso do tema ambiental (critério), atendendo às medidas de mitigação, é ponderado por esse fator $\boldsymbol{K}$.

\subsection{Predição de impactes}

A predição de impactes implica a quantificação dos impactes previsíveis. A quantificação de impactes consiste na determinação da sua magnitude e na avaliação da sua significância. Uma medida dessa magnitude pode ser dada pelo valor do indicador de impacte ambiental selecionado. Para determinação desse valor pode recorrer -se, para além da informação constante no projeto técnico, a modelos de simulação (ex.: modelo de dispersão de poluentes no ar/atmosfera) que permitem estimar a variação de um descritor ambiental, por exemplo a concentração de CO provocada pelo tráfego de uma estrada sobre numa área envolvente à estrada. Para isso o SIG pode fornecer os dados, espaciais e alfanuméricos, de entrada para esses modelos e expor os resultados. Esses modelos de simulação são baseados em formulações matemáticas e algorítmicas, alguns dos quais estão já automatizados em programas computacionais. Nalguns casos, no entanto, essa magnitude é determinada recorrendo apenas a simples operações de análise espacial, ou a operações de geoprocessamento disponibilizadas pelo SIG.

O ArcGis ${ }^{\circledR}$ disponibiliza atualmente um ambiente de geoprocessa- 
mento que permite a construção de modelos SIG para desempenharem repetidamente um conjunto de operações de geoprocessamento. Para tal disponibiliza o ModelBuilder, um interface visual onde são gerados os diagramas de fluxo dessas operações (ORMSBY et al., 2004). Disponibiliza também mais quatro formas de automatizar operações ou um conjunto (diagrama de fluxo) de operações SIG de geoprocessamento: (1) a partir da ferramenta na caixa de diálogo; (2) usando sbortcut numa linha de comando de uma janela; (3) escrevendo scripts; (4) através da criação de ferramentas personalizadas desenvolvidas com linguagem de programação $C++, V B, . N E T, C \#$, com código embebido, que manipulem Arcobjects (conjunto de objetos computacionais especialmente concebidos para programação com as aplicações ArcGis Desktop (BURKE, 2003), (ORMSBY et al., 2004).

A Figura 4 mostra, a título de exemplo, o fluxograma do modelo SIG construído para o caso de estudo, denominado Mod_Flora, o qual permite gerar o map layer.

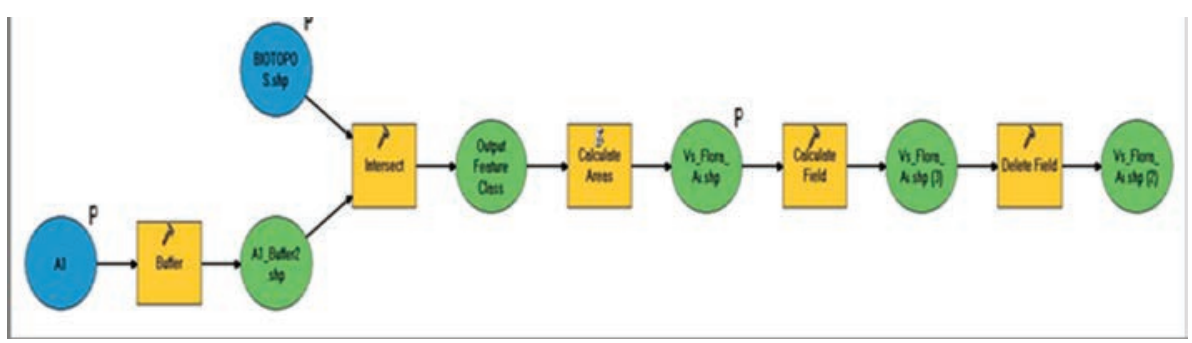

Figura 4 - Fluxograma do Mod_Flora

É assim possível criar automática e repetidamente map layers com a distribuição espacial da variação dum descritor ambiental, extrair daí um indicador ambiental (critério) e o respetivo valor (performance de cada alternativa segundo esse critério). Nas Figuras 5 e 6 mostram -se alguns mapas gerados no SIG, a partir dos quais foi possível extrair os valores dos indicadores (ex. indicador ambiental Valor Ecológico da Flora). 


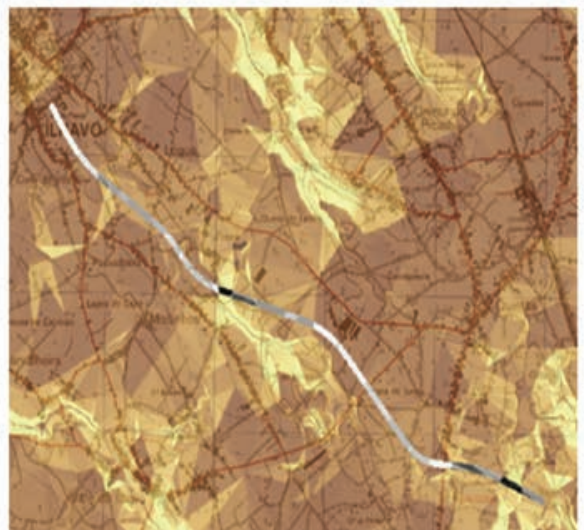

Figura 5 - Mapa da erosão média para a A1

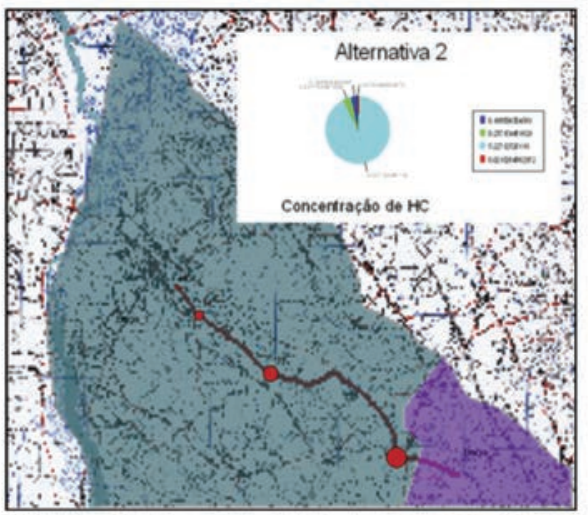

Figura 7 - Concentração de HC para a Alternativa A2

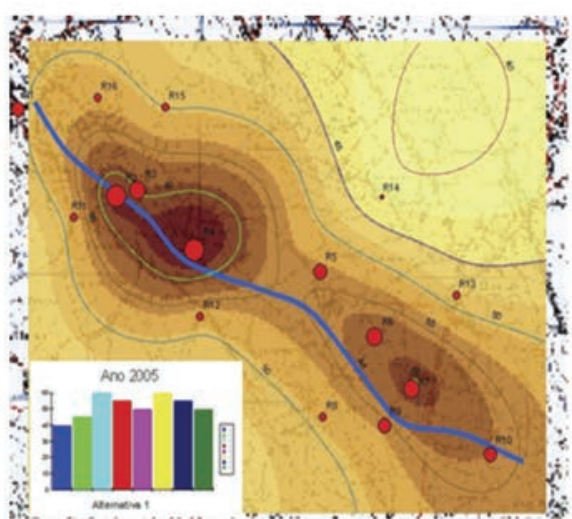

Figura 9 - Mapa e Linha de Contorno de Ruído para a Alternativa 1 e ano 2005

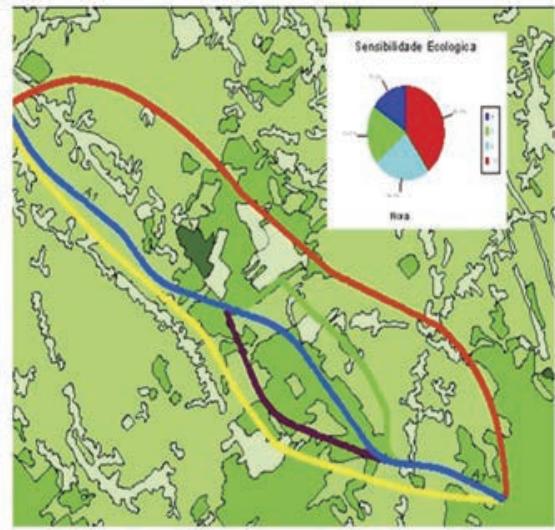

Figura 6 - Mapa da sensibilidade ecológica, flora

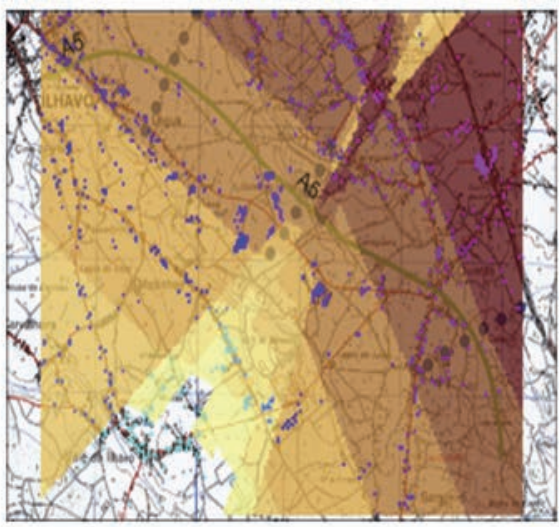

Figura 8 - Distribuição espacial da concentração de CO gerada pela Alternativa 5

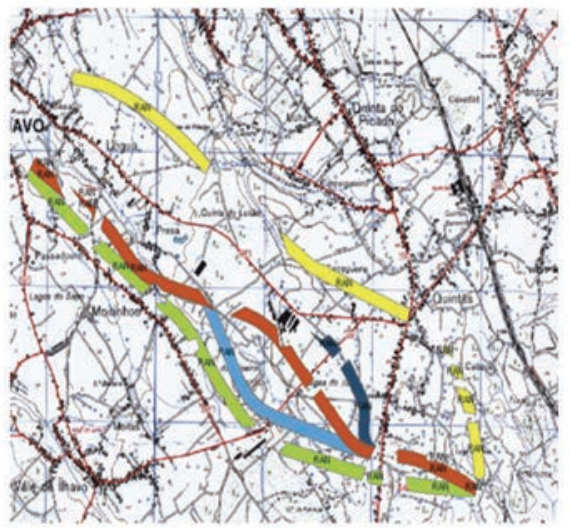

Figura 10 - Áreas de RAN, REN e PP afetadas, por cada alternativa 


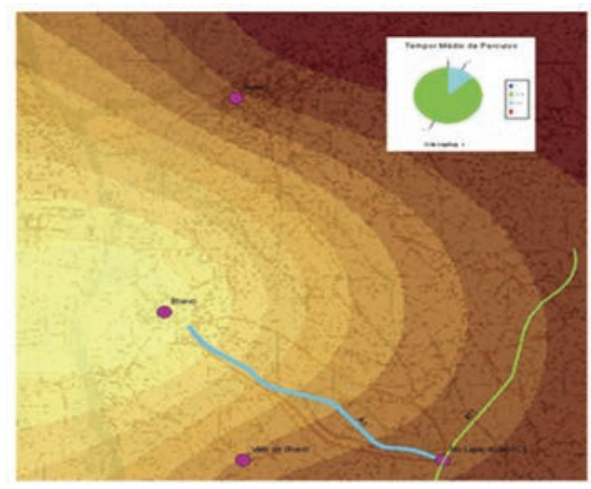

Figura 11 - mapa raster GanhoTempo, para alternativa 1

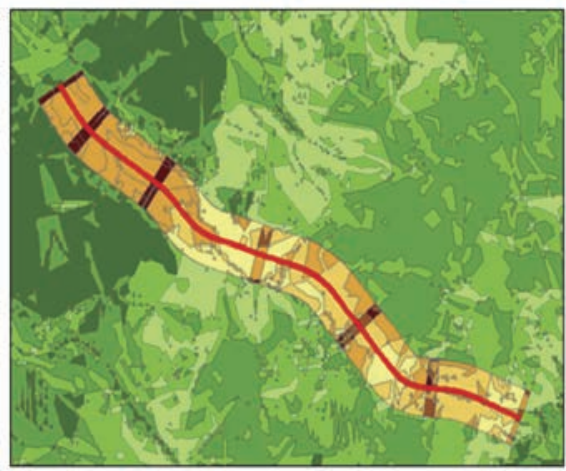

Figura 12 - Zonas de Maior Impacte Visual, sobre Mapa de Sensibilidade da Paisagem

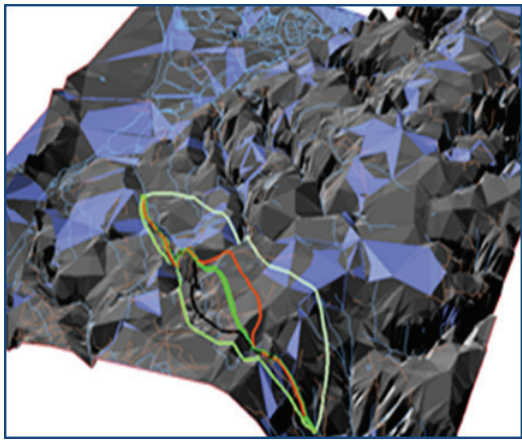

Figura 13 - Visualização dos traçados

A significância dos impactes tem a ver com a importância que lhes é atribuída pelos técnicos, opinião pública, instituições, etc. (LOOIJEN, 2004), (ANTUNES et al., 2004) Ou seja, para a tomada de decisão sobre qual a alternativa a escolher interessa ponderar esta importância. Na metodologia a computação da importância que é atribuída a cada tema ou elemento ambiental, segundo determinados critérios, atenuada ou não pelas medidas de mitigação efetivamente a aplicar, vai servir de base à definição dos pesos a usar na análise multicritério. Assim, todos os temas ou elementos ambientais vão ser avaliados sob uma base comum de comparação. Isto é, todos eles são avaliados numa escala de 1 a 6 , em função (MOLINES \& CHEVALLIER, 2002):

Do seu potencial ambiental - Tendo em conta a situação atual e a 
sua evolução na ausência da implementação do projeto, o aspeto (tema ou elemento) ambiental apresenta um potencial local, regional, nacional, ou mundial, em relação às preocupações ecológicas, urbanísticas, patrimoniais, culturais, sociais, estéticas, técnicas, económicas, etc. Esta quantificação tem em conta princípios científicos formais, e incorpora uma atenção a consciência e ao peso que lhe é dado pela sociedade;

Da sua sensibilidade à introdução do projeto - É avaliado aqui o risco de impacte sobre o aspeto ambiental induzido pela introdução do projeto;

Ao risco de impacte após mitigação - Este peso é construído em duas etapas. A primeira corresponde à avaliação desses riscos de impacte, mesmo tendo em conta a introdução de todas as medidas de mitigação possíveis, independentemente do custo financeiro, numa escala de 1 a 3. $\mathrm{Na}$ segunda etapa este valor sofre uma transformação linear para a escala ponderada de 1 a 6 , através do operador $(2-K)$. Isto é, $P M(K) m=\times$ 2 - , sendo $M$ a graduação do risco de impacte após a adoção de todas as medidas de mitigação possíveis, na escala de 1 a 3, e Pm a importância atribuída ao tema ou elemento ambiental, que cresce com a diminuição da implementação de medidas de mitigação, na escala comum de 1 a 6 .

Assim, dum nível 1 que caracteriza um elemento pouco sensível ou de importância apenas local, até ao nível 6 que põe em evidência a presença de uma componente tipo "património mundial”, são definidos 6 valores. O peso para cada elemento dentro do tema ambiental é a correspondente proporção relativa do somatório dos três pesos anteriores, dentro do tema. Esse peso da componente é distribuído uniformemente pelos indicadores ambientais dessa componente. Computacionalmente estas operações podem ser realizadas pela rotina em código $V B$ invocada a partir duma caixa de diálogo de atribuição de pesos, sendo guardados numa tabela $d$ Base ${ }^{\circledR}$ relacionada com as tabelas de temas e elementos ambientais. Opcionalmente aos pesos "técnicos", definidos anteriormente, pode optar -se por atribuir pesos "voluntaristas" a cada componente baseado na sensibilidade do utilizador.

Os temas e respetivos indicadores ambientais analisados foram os seguintes: 
a) Geomorfologia e Geologia $13 \S \S$ Relevo e Topografia §§ Estabilidade de Vertentes b) Recursos Hidricos $§ \S$ Fluxo de Águas Superficiais §§ Fluxo de Águas Subterrâneas §§ Qualidade das Águas c) Solos §§ Erosão §§ Impermeabilização do solo d) Atmosfera §§ Qualidade do Ar e) Sistemas Ecológicos $\S \S$ Flora $\S \S$ Fauna f) Ocupação do Solo $\S \S$ Agrícola $\S \S$ Floresta $\S \S$ Habitacional §§ Indústria e Serviços g) Estética $§ \S$ Paisagem b) Ambiente Sonoro $\S \S$ Ruido i) Condicionante e Ordenamento §§ RAN §§ REN §§ Planos de Pormenor j) Socioeconómico $\S \S$ Acessibilidade $\S \S$ População ativa $\S \S$ Expropriações

\section{Geomorfologia e Geologia}

Para avaliação da magnitude dos impactes sobre este tema e os seus elementos ambientais foram selecionados vários indicadores ambientais. Para o elemento Relevo e Topografia foi selecionado o indicador Volume Total de Escavação (VTE), porque é uma "medida" do "rasgo" que é feito no terreno. O seu valor é obtido por consulta ao projeto rodoviário. Para o elemento Estabilidade de Vertentes foram selecionados os indicadores Altura Máxima de Talude (AMT) - porque está relacionado com a inclinação do talude - sendo o seu valor também obtido por consulta ao projeto rodoviário, e o indicador Erosão Média (EM) já que a ocorrência de nascentes de água nos taludes de escavação, associados à erosão provocada pelo escoamento superficial, são suscetíveis de provocar instabilidade de taludes. Para a sua quantificação recorreu -se à construção de um Mapa de Erosão do Solo, recorrendo às ferramentas e funcionalidades do ArcGis ${ }^{\circledR}$ e da extensão Spatial Analyst ${ }^{\circledR}$ (SPA). Como exemplo mostra -se na ura 5, o Mapa da Erosão Média para a alternativa A1.

\section{Recursos Hidricos}

Para o tema ambiental "Recursos Hídricos" foram selecionados os elementos ambientais: Fluxo das águas superficiais; Fluxo de águas subterrâneas; Qualidade das águas superficiais; Qualidade das águas subterrâneas. Para o primeiro elemento foram escolhidos os indicadores ambientais Número de Passagens Hidráulica Afetadas (PHA), e Volume de Escoamento Superficial Direto (VESD). Para o segundo elemento foi escolhido o indicador Poços e Furos Diretamente Afetados (PFDA). Para o terceiro elemento ambiental Qualidade das Águas Superficiais foram 
definidos cinco indicadores: Acréscimo de Concentração de partículas sólidas (SST); Acréscimo de Concentração de Hidrocarbonetos (HC); Acréscimo de Concentração de Cádmio (Cd); Acréscimo de Concentração de Cobre (Cu); Acréscimo de Concentração de Zinco ( $\mathrm{Zn}$ ). A título exemplificativo apenas se considerou a concentração de (HC), já que a sua concentração é a que mais nitidamente ultrapassa os limites legais. Para o último elemento Qualidade das Águas Subterrâneas considerou -se o indicador Distância à Mina das Castelhanas. Como exemplo mostra -se na Figura 7 o mapa da Concentração de HC para a Alternativa A2.

Solos

Para avaliação da magnitude dos impactes sobre este tema foram selecionados os elementos Erosão e Impermeabilização de Solo. Para o elemento Erosão definiu -se o indicador ambiental Erosão Total (ET) - já que esta afeta a qualidade do solo. Para o elemento ambiental Impermeabilização considerou -se o indicador Área Total Impermeabilizada (ATI) uma vez que ela determina a ausência de infiltração imediata no terreno de uma boa parte da precipitação. Para quantificar o valor destes indicadores utilizam -se os dados estatísticos gerados no modelo SIG Modelo de Erosão gerado no ModelBuilder do ArcGis®.

\section{Atmosfera}

Para o presente tema ambiental foi escolhido o elemento ambiental Qualidade do ar e os respetivos indicadores ambientais Concentração de CO sobre o edifício A (CCOA) e Concentração de CO sobre o edifício B (CCOB) .Como exemplo mostra -se na Figura 8 o mapa da Distribuição espacial da concentração de CO gerada pela Alternativa 5

\section{Sistemas Ecológicos}

Para determinação da magnitude dos impactes sobre este tema selecionaram -se os elementos ambientais Flora e Fauna. Para o primeiro foi escolhido o indicador ambiental Valor Ecológico da Flora (VEF) e para o segundo os indicadores Valor Ecológico dos Mamíferos (VEM) e Valor Ecológico das Aves (VEA), afetados pela estrada. Como exemplo mostra -se na Figura 6 o Mapa da sensibilidade ecológica, flora. Para 
a quantificação desses impactes construiram -se os modelos SIG, Mod_ Flora e Mod_Fauna, apoiados nas capacidades de geoprocessamento do ArcGis ${ }^{\circledR}$, e nos seguintes pressupostos teóricos: O primeiro efeito duma estrada é a perda não negligenciável de habitats, e o desaparecimento de ecossistemas situados sobre o traçado. O segundo efeito é o corte na paisagem e em fragmentos de habitats - com efeito só as aves conseguem voar - pelo que as outras espécies se vêm impedidas de a atravessar. O terceiro efeito é a recriação de novos ecossistemas dentro do "ambiente" da estrada (GASSER et al., 2004).

Ocupação do Solo

Para avaliação da magnitude dos impactes sobre este tema selecionaram -se os seguintes elementos e indicadores ambientas: O elemento Ocupação Agrícola e o indicador ambiental Total de Área Agrícola Afetada (AAA); o elemento Ocupação Florestal e os indicadores Total de Área Florestal Afetada (AFA), Total de Área de Floresta de Produção Afetada (AFPA), e Total de Área de Matos Afetada (AMA); o elemento Ocupação Habitacional e o indicador Total de Área Habitacional Afetada (AHA); o elemento Ocupação Industria e Serviços e o indicador Total de Área de Industria e Serviços (AISA). Para quantificar o valor destes indicadores utilizaram -se os dados estatísticos gerados pelo Modelo SIG AreasAfectadas que geram o mapa Areas de RAN, REN e PP afetadas, por cada alternativa, apresentado na Figura 10.

\section{Estética}

Para avaliação da magnitude dos impactes sobre este tema, selecionou -se o elemento Paisagem, tendo como indicador único o Índice de Paisagem (IPS) afetada. Este índice agrega o somatório para todas as zonas homogéneas de impacte visual - graduadas de 1 a 12 - do produto da sensibilidade média da paisagem, numa largura de 500 metros - para cada zona - pela incidência graduadas das características do projeto no troço atravessando essa zona homogénea. Para a sua quantificação e visualização, construiram - se os modelos SIG, Sensibilidade da Paisagem e Degradação Visual da Paisagem a partir do qual foi gerado o mapa Zonas de Maior Impacte Visual, sobre Mapa de Sensibilidade da Paisagem, conforme se mostra na Figura 12, tendo em conta os se- 
guintes pressupostos teóricos: A paisagem pode ser considerada como uma expressão das atividades do homem sobre um determinado sistema biofísico. Constitui, assim, uma entidade mutável cuja sustentabilidade depende necessariamente do equilíbrio dinâmico das interações operadas sobre esse sistema. A sua análise depende do conhecimento de fatores intrínsecos da paisagem, tais como "fatores independentes da ação humana e de âmbito biofísico, como sejam a geologia, a morfologia do terreno, recursos hídricos, solos, biocenoses entre outros" (ARQPAIS, 2001), e de fatores extrínsecos que constituem "aspetos de ordem sociocultural, que atuam ao nível do sistema biofísico e que se refletem em formas de apropriação do território, concorrendo para a caracterização e/ou definição da paisagem, como sejam os modelos de povoamento, a tipologia dos sistemas culturais, entre outros" (ARQPAIS, 2001).

\section{Ambiente Sonoro}

Para avaliação da magnitude dos impactes sobre este tema, selecionou -se o elemento Ruído de Tráfego e dois indicadores absolutos e dois indicadores relativos, respetivamente Área total de zona urbana exposta a um LAeq $>=55 \mathrm{~dB}(\mathrm{~A})$ para o ano do projecto (AUL55_0); Área total de zona urbana exposta a um LAeq $>=55 \mathrm{~dB}(\mathrm{~A})$ para o ano horizonte de projecto (AUL55_30), e mais os dois relativos à situação actual (\% AUL55_0) e (\%AUL55_30). Para automatizar a quantificação e visualização, construiu -se um modelo SIG denominado LAeq $>55 \mathbf{d b A}$, apoiados nas capacidades de geoprocessamento do ArcGis ${ }^{\circledR}$ e nos pressupostos tecnicos -legais estipulados no Regulamento Geral sobre o Ruído, publicado pelo D.L 09/2007 de 17 de Janeiro e outras publicações técnicas da especialidade. Como exemplo mostra -se na Figura 9 o Mapa e Linha de Contorno de Ruído para a Alternativa 1 e ano 2005.

\section{Condicionante e Ordenamento}

Para quantificação de impactes sobre este tema foram selecionados os elementos ambientais RAN e REN dada sua importância para a preservação do ecossistema ambiental. A descriminação destas áreas, ao nível local (concelhio) é feita no PDM (Plano Diretor Municipal). Foi também selecionado o elemento Planos de Pormenor pela sua implicação a nível do ordenamento local. Segundo (ARQPAIS), no concelho de 
Ílhavo, a data (2001), estavam definidos 4 Planos de Pormenor: Plano de Pormenor de Cimo da Vila; Plano de Pormenor dos 4 Caminhos; Plano de Pormenor da Légua/Presa; Plano de Pormenor da Zona Industrial das Ervosas; Plano de Pormenor das Cancelas. Como indicadores de impacte ambiental foram selecionados: Área de RAN Afectada (ARANA); Área de REN Afectada(ARENA); Área de PP Afectada (APPA). Os seus valores traduzem uma magnitude do impacte nas Condicionantes (RAN e REN) e no Ordenamento (Planos de Pormenor existentes). Para quantificação desses indicadores, construiu -se no ModelBuider do ArcGis ${ }^{\circledR}$ o modelo SIG Cond_Afecta que permite automatizar a criação de map layers para análise e visualização, conforme se mostra na Figura 10 - Áreas de RAN, REN e PP afetadas, por cada alternativa.

\section{Socioeconómico}

Para o caso concreto de um projeto rodoviário, são normalmente associados, pelos especialistas, os seguintes efeitos principais: (1) Alterações da acessibilidade; (2) Condições de circulação; (2) Expropriações de propriedade; (3) Afetação de parcelas com produção agrícola ou florestal; (4) Constituição de barreiras; (5) Desenvolvimento de novas atividades; (6) Alteração da ocupação do solo (7); Alteração ao nível da população ativa e interferência com atividades económicas e equipamentos coletivos. Destes, para exemplo de integração em ambiente SIG, e avaliação multicritério - adaptados ao exemplo de estudo - foram selecionados os elementos ambientais Acessibilidades, Expropriações e População Ativa, tomando como indicadores de impacte ambiental, respetivamente: Ganho de Tempo (GT); Emprego Induzido (EI); Valor de Expropriação Média (VEM); e Valor de Expropriação Total (VETO). Como exemplo mostra -se na Figura 11 o mapa raster Ganho'Tempo para a alternativa 1.

\subsection{Avaliação de alternativas}

A fase de avaliação de alternativas tem por objetivo a ordenação das alternativas desde a "ambientalmente mais favorável" até à mais adversa. Essa ordenação é o culminar do processo de avaliação multicritério suportado pelos métodos MCAD. No presente trabalho utilizou -se basicamente o ELECTRE III (MAYSTRE et al., 1994) dado a sua especial adequação 
ao fim em causa. O algoritmo deste método está disponível em http:// kreation.dec.uc.pt/matrix.html, uma base de métodos de apoio à decisão multicritério que oferece uma interface web -browser para a edição interativa de problemas (matriz de decisão, parâmetros), centralizando vários algoritmos multiatributo (Simple Additive Weighting, TOPSIS, VIKOR, ELECTRE I/III/IV/Tri, entre outros).

Conceptualmente o processo de avaliação de alternativas, por tema, inicia -se com a ativação de um menu "Avaliação Multicritério" que dá acesso a uma caixa de diálogo onde se pode optar pela "Avaliação por Tema Ambiental” ou “Avaliação Geral”. A primeira opção chama uma rotina para preenchimento da matriz de decisão e definição 17 dos pesos e limiares de preferência, indiferença e veto, para cada Tema Ambiental (ex. Figura 14 abaixo, Sistemas Ecológicos).

\begin{tabular}{|c|c|c|c|c|c|}
\hline \multirow{2}{*}{\multicolumn{3}{|c|}{$\begin{array}{l}\text { TEMA } \\
\text { Elementos Ambientais }\end{array}$}} & \multicolumn{3}{|c|}{ SISTEMAS ECOLOGICOS } \\
\hline & & & \multirow{2}{*}{$\begin{array}{c}\text { Flora } \\
7\end{array}$} & \multicolumn{2}{|c|}{ Fauna } \\
\hline \multirow{5}{*}{$\begin{array}{l}\frac{s}{0} \\
z \\
\frac{d}{0} \\
\frac{\underline{u}}{z} \\
\frac{0}{\omega}\end{array}$} & \multirow{4}{*}{ 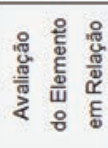 } & $\Sigma$ & & \multicolumn{2}{|c|}{8} \\
\hline & & Ao seu potencial ambiental & 2 & \multicolumn{2}{|l|}{2} \\
\hline & & Á sua sensibilidade á introduçăo do projeto & 2 & \multicolumn{2}{|l|}{3} \\
\hline & & Ao Risco de Impacte após mitigação & 3 & \multicolumn{2}{|l|}{3} \\
\hline & & Pesos dos Indicadores (\%) & 46 & 27 & 27 \\
\hline \multicolumn{3}{|c|}{ Indicadores } & Flora $\left(10^{4}\right)$ & Mamiferos $\left(10^{4}\right)$ & Aves \\
\hline \multicolumn{3}{|l|}{ A1 } & 1530 & 21466 & 2777 \\
\hline \multicolumn{3}{|l|}{ A2 } & 1572 & 21606 & 9389 \\
\hline \multicolumn{3}{|l|}{ A3 } & 1555 & 21908 & 2830 \\
\hline \multicolumn{3}{|l|}{ A4 } & 1527 & 13953 & 10419 \\
\hline \multicolumn{3}{|l|}{ A5 } & 1606 & 22575 & 10731 \\
\hline \multicolumn{3}{|c|}{ Limiar, q } & 16 & 1724 & 1530 \\
\hline \multicolumn{3}{|c|}{ Limiar, $\mathbf{p}$} & 32 & 3445 & 3060 \\
\hline
\end{tabular}

Figura 14 - Matriz de decisão para o tema Sistemas Ecológicos

A dimensão da matriz é previamente definida, durante o desenrolar da rotina VBA, ainda na fase de Scoping e Identificação de Impactes, sendo o número de linhas igual ao número de alternativas e o número de colunas é igual ao número de critérios ou atributos ambientais, representados pelos Indicadores de Impacte Ambiental, selecionados para esse tema.

Os pesos são guardados em tabelas dBase ${ }^{\circledR}$ ou Access ${ }^{\circledR}$. Os limiares de indiferença, preferência e veto podem ser atribuídos de uma forma 
voluntarista ou através de uma função. Definida a matriz de decisão (p.ex. Figura 14 - Matriz de decisão para o tema Sistemas Ecológicos), o método ELECTRE III será aplicado retornando duas preordenações parciais, uma para cada destilação, e uma preordenação final dada pela "intersecção" destas duas.

No caso de se optar pela “Avaliação Global” (Figura 15), a matriz de decisão terá as $m$ linhas das alternativas e um número de colunas $n$ "critérios" igual ao dobro do número dos temas ambientais a avaliar $\mathrm{T}$ correspondendo a duas colunas por cada tema, uma para a ordenação de preferências das alternativas da destilação descendente e outra para a ordenação da destilação ascendente. No caso de estudo foram selecionados dez temas pelo que a matriz de decisão será de vinte vezes cinco. O valor dos atributos ou desempenhos desta matriz são definidos recorrendo a uma escala que varia de 0 a 20.

\begin{tabular}{|c|c|c|c|c|c|c|c|c|c|c|c|c|c|c|c|c|c|c|c|c|c|c|}
\hline \multirow{2}{*}{\multicolumn{3}{|c|}{ Elementos Ambientais }} & \multicolumn{20}{|c|}{ GERAL } \\
\hline & & & \multirow{2}{*}{\multicolumn{2}{|c|}{ 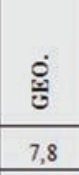 }} & \multicolumn{2}{|c|}{$\bar{\beth}$} & \multicolumn{2}{|c|}{ 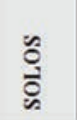 } & \multicolumn{2}{|c|}{$\sum_{\frac{1}{2}}$} & \multicolumn{2}{|c|}{ 畩 } & \multicolumn{2}{|c|}{ ڤ్ } & \multicolumn{2}{|c|}{ 高 } & \multicolumn{2}{|c|}{ 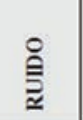 } & \multicolumn{2}{|c|}{ そิ } & \multicolumn{2}{|c|}{$\sum_{0}$} \\
\hline \multirow{5}{*}{ 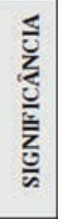 } & \multirow{5}{*}{ 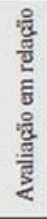 } & $\Sigma$ & & & \multicolumn{2}{|c|}{8,8} & \multicolumn{2}{|c|}{7} & \multicolumn{2}{|c|}{7,8} & \multicolumn{2}{|c|}{8} & \multicolumn{2}{|c|}{7,8} & \multicolumn{2}{|c|}{5,5} & \multicolumn{2}{|c|}{5,5} & \multicolumn{2}{|c|}{11} & \multicolumn{2}{|c|}{5,1} \\
\hline & & P.Amb. & \multicolumn{2}{|c|}{2} & \multicolumn{2}{|c|}{2} & \multicolumn{2}{|c|}{2} & \multicolumn{2}{|c|}{3} & \multicolumn{2}{|c|}{2} & \multicolumn{2}{|c|}{3} & \multicolumn{2}{|c|}{2} & 2 & & 4 & 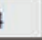 & 2 & 2 \\
\hline & & S.I.P & & & 3 & & 3 & & 2 & & 3 & & 3 & & 2 & & 2 & & s & 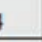 & 2 & 2 \\
\hline & & RI.A.M & & 8 & 3 & & 2 & & 2 & & 3 & & 2,7 & & 1 & 5 & 1, & & 3 & 3 & 1, & 1 \\
\hline & & Pesos $(\%)$ & & 0 & & & 9 & & 1 & & 1 & & 10 & & $\varepsilon$ & 3 & 8 & & 1 & 5 & 7 & 7 \\
\hline $\begin{array}{l}\text { Indic } \\
\text { (Dest }\end{array}$ & $\begin{array}{l}\text { dores } \\
\text { ações }\end{array}$ & & D & A & 0 & A & 0 & A & 0 & A & 0 & A & 0 & A & D & A & 0 & A & 0 & A & 0 & A \\
\hline Al & & & 0 & 0 & 15 & 15 & 15 & 15 & 5 & 10 & 10 & 10 & 15 & 10 & 10 & 10 & 15 & 15 & 10 & 5 & 0 & 0 \\
\hline A2 & & & 10 & 10 & 5 & 0 & 0 & 0 & 0 & 0 & 5 & 5 & 5 & 0 & 0 & 0 & 10 & 10 & 15 & 10 & 10 & 15 \\
\hline A3 & & & 0 & 0 & 0 & 0 & 5 & 5 & 5 & 5 & 10 & 10 & 10 & 5 & 10 & 10 & 10 & 10 & 0 & 0 & 10 & 5 \\
\hline A4 & & & 3 & 5 & 15 & 10 & 5 & 5 & 10 & 15 & 10 & 10 & 20 & 15 & 10 & 10 & 0 & 0 & 15 & 5 & 5 & 10 \\
\hline A5 & & & 15 & 15 & 10 & 5 & 10 & 10 & 10 & 15 & 10 & 10 & 0 & 0 & 5 & 5 & 5 & 5 & 5 & 0 & 0 & 15 \\
\hline Limi: & & $(20 / \mathrm{m}-1)$ & 5 & 5 & 5 & 5 & 5 & 5 & 5 & 5 & 5 & 5 & 5 & 5 & 5 & 5 & 5 & 5 & 5 & 5 & 5 & 5 \\
\hline Limi & $r, p$ & (2q) & 10 & 10 & 10 & 10 & 10 & 10 & 10 & 10 & 10 & 10 & 10 & 10 & 10 & 10 & 10 & 10 & 10 & 10 & 10 & 10 \\
\hline v(vet & & (3q) & 15 & 15 & 15 & 15 & 15 & 15 & 15 & 15 & 15 & 15 & 15 & 15 & 15 & 15 & 15 & 15 & 15 & 15 & 15 & 15 \\
\hline
\end{tabular}

Figura 15 - Matriz de decisão global, 20 critérios

Trata -se da normalização linear para uma escala comum da classificação das preordenações: 


$$
r_{i j}=[20 / m-1] \times X_{i j}-[20 / m-1]
$$

sendo $X_{i j}$ a classificação ordinal da alternativa $i$ na preordenação $j$, e $m$ o número de alternativas. Agora, para cada tema, atribui -se uma pontuação de 1 a 6 segundo os critérios: do seu potencial ambiental; da sua sensibilidade à introdução do projeto; ao risco de Impacte após mitigação. Os pesos são distribuídos igualmente pelos dois critérios (ordenações) de cada tema. Também aqui é possível optar pelos pesos "técnicos" ou "voluntaristas". O resultado são duas preordenações parciais, uma para a destilação ascendente e outra para a destilação descendente, que são agregadas numa única preordenação final, conforme se mostra na Figura 16.

\begin{tabular}{|l|l|l|}
\hline \multicolumn{1}{|c|}{ (1) } & \multicolumn{1}{|c|}{ (2) } & \multicolumn{1}{c|}{ (3) } \\
\hline $\mathrm{Al}, \mathrm{A5}$ & $\mathrm{A} 1, \mathrm{~A} 5$ & $\mathrm{Al}$ \\
\hline $\mathrm{A4}$ & $\mathrm{A} 4$ & $\mathrm{A4,A5}$ \\
\hline $\mathrm{A} 2$ & $\mathrm{~A} 2$ & $\mathrm{A2,A3}$ \\
\hline $\mathrm{A3}$ & $\mathrm{A3}$ & \\
\hline
\end{tabular}

Figura 16 - Preordenação final

Esses resultados do método ELECTRE III são visualizados numa janela separada do ArcView®. Para isso é construído um botão personalizado no interface do ArcView ${ }^{\circledR}$ que, através do método VB shell, estabelece a comunicação com o referido servidor de algoritmos.

\subsection{Análise de sensibilidade}

Uma análise de sensibilidade mostra que a alternativa (A1) é a "ambientalmente mais favorável" já que aparece sempre, isolada ou em conjunto com outra, à cabeça das preordenações. Já as alternativas (A2) e (A3), aparecendo consistentemente na cauda das preordenações, podem ser consideradas as "ambientalmente mais adversas". A Figura 13 mostra uma modelação do terreno no ArcScene® com o traçado "ambientalmente mais favorável" realçado a verde. 


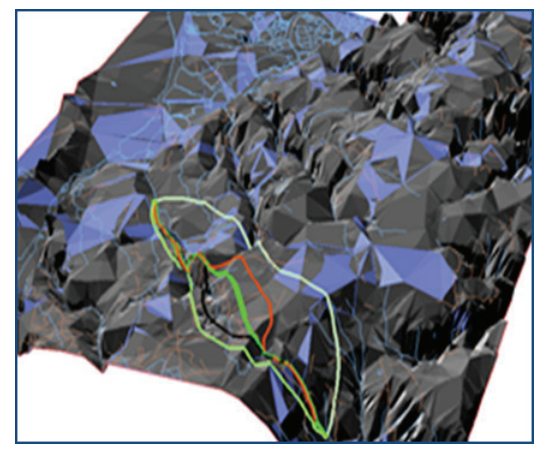

Figura 13 - Visualização dos traçados (repetida para conveniência)

\section{CONCLUSÕES E DESENVOLVIMENTOS FUTUROS}

A proposta metodológica apresentada neste trabalho representa um primeiro passo para o desenvolvimento de um Sistema de Apoio à Decisão Espacial Multicritério (SADE -MC) no domínio ambiental. Considerando o trabalho desenvolvido e os resultados obtidos sugere -se para futuros trabalhos a prossecução da integração SIG -MC com vista à construção do supra -citado SADE -MC, que se constituará como um efetivo programa computacional de apoio à decisão para diversos projetos sujeitos a EIA.

Essa integração poderá ser desenvolvida em ambiente SIG (desktop ou Server) - o que pressupõe embeber no SIG a codificação de vários algoritmos dos métodos multiatributo ou uma ligação web a uma base de métodos de apoio à decisão multicritério, como por exemplo a disponível em http://kreation.dec.uc.pt/matrix.html, anteriormente referida. Isso permitirá carrear cientificidade e objetividade para as tomadas de decisão, no domínio ambiental, sobre os empreendimentos em avaliação, já que a subjetividade sempre presente nos estudos e conclusões dos EIA será substancialmente reduzida.

\section{AgRADECIMENTOS}

Este trabalho foi parcialmente financiado pela Fundação Portuguesa para a Ciência e Tecnologia (FCT) sob a Ref "PEst -OE/ EEI/UI308/2014", pelo projeto Energy and Mobility for Sustainable Regions (EMSURE) - Ref ${ }^{a}$ 
CENTRO -07 -0224 -FEDER -002004, e enquadra -se na iniciativa Energy for Sustainability da Universidade de Coimbra.

\section{BIBLIOGRAFIA}

ABRANTES, Graça (1998) - "Conceitos de Sistemas de informação geográfica". Instituto Superior de Agronomia. Universidade Técnica de Lisboa, Portugal. Disponível online no endereço url: http://www.isa.utl.pt/dm/sigdr/sigdr01 -02/SIGconceitos.html (acedido em 28 Março, 2014).

AGRAWAL, Mohan et al. (2003) - "Impact Assessment on Soil Erosion due to Highway Construction using GIS". in Electronic Journal of Geotechnical Engineers. Disponível online no endereço url: http://www.ejge.com/2003/ Ppr0339/ (acedido em 28 Março, 2004).

ALMEIDA, José \& COUTINHO-RODRIGUES, João (2001) - "Estudo de Impactes Ambientais com SIG. Simulação para o Caso da Co -Incineração de Souselas". Instituto de Engenharia de Sistemas e Computadores de Coimbra (INESCC), $\mathrm{N}^{\circ}$ 15. Disponível online no endereço url: http://www.inescc.pt/documentos/RR2003_15.pdf (acedido em 28 Março, 2014).

ANTUNES, Paula et al. (2001) - "The Application of Geographical Information Systems to determine environmental impact significance". In Environmental Impact Assessment Review. Disponível online no endereço url: http:// www.sciencedirect.com/science/article/pii/S0195925501000907 (acedido em 28 Março, 2014).

ARQPAIS, Consultores de Arquitetura Paisagista e Ambiente, Lda., (2001) - "Estudo de Impacte Ambiental da SCUT da Costa de Prata. Lanço ICI * Mira/Aveiro. Sublanço Vagos /Aveiro Sul. Ligação a Ílhavo".

BOOTH, Bob (2002) - Using ArcGis ${ }^{\circledR}$ 3D Analyst . ESRI Press, Redland, California, $212 \mathrm{p}$.

BURKE, Robert (2003) - Getting to know arcobjects, programing arcgis@ with vba. ESRI PRESS, Redland, Califórnia, 422 p.

CABRAL, Pedro (2001) - "Sistemas Espaciais de Apoio à Decisão. O Sistema de Apoio ao Licenciamento da Direcção Regional do Ambiente do Alentejo”. Tese de Mestrado em Sistemas de informação geográfica. Instituto Superior Técnico. Lisboa, Portugal. Disponível online no url: www.isegi.unl.pt/ labnt/tese/ tesemaio2001_ pedrocabral. pdf (acedido em 28 Março, 2014).

CÂMARA, Gilberto \& QUEIROZ, Gilberto (2001) - "Arquitectura de Sistemas de informação geográfica”. Disponível online no endereço url: http://www. dpi.inpe.br/gilberto/livro/introd/cap3 -arquitetura.pdf (acedido em 28 Março, 2014). 
CAMPOS, Luís et al. (1999) - Programação em Visual Basic 6. FCA - Editora de Informática, Lda. Lisboa, Portugal, 464 p.

CHAKHAR, Salem \& MARTEL, Jean-Marc (2001) - "Toward a Spatial Decision Support Sytem: Multi -Criteria Evaluation Functions into Geographical Information Sytems". LAMSADE, Université Paris Dauphine, France. Disponível online no endereço url: http://www.lamsade.dauphine.fr/ chakhar/papers/CM -ANNALES2a.pdf (acedido em 28 Março, 2014).

CHAKHAR, Salem \& MARTEL, Jean-Marc (2003) - "Enhancing Geographical Information Systems Capabilities with Multi -Criteria Evaluations Functions". Journal of Geographic Information and Decisions Analysis, Vol. 7, $\mathrm{N}^{\circ} 2$, 47 -11.

COE, Davis et al. (1998) - "User's Guide for CL4. US". Environmental Protection Agency. Disponível online no endereço url: http://www.epa.gov/scram001/ index.htm (acedido em 28 Março, 2014).

COUTINHO -RODRIGUES, João (2003) - Gestão de Empreendimentos. IDTec, Engenharia e Inovação, Lda. Coimbra, Portugal, 480p.

DECRETO -LEI n. ${ }^{\circ}$ 09/2007 de 17 de Janeiro. Diário da República, $1 .^{a}$ série - N. ${ }^{\circ}$ 12 - 17 de Janeiro de 2007. Lisboa. Portugal

ERICKSON, Paul (1994) - A Pratical Guide to Environmental Impact Assessment. Academic Press San Diego, Califórnia, USA, 266p.

ESRI Portugal (2004) - Sistemas de informação geográfica. Sebenta do Curso de Introdução ao ArcGis, Nível I. Lisboa, Portugal.

ESRI Portugal (2005) - Sistemas de informação geográfica. Sebenta do Curso de Introdução ao ArcGis, Nível II. Lisboa, Portugal.

FAO, Food and Agriculture Organization of the United Nations (2004) Environmental impact assessment and environmental auditing in the pulp and paper industry. Disponível online no endereço url: http://www.fao. org/docrep/005/v9933e/ v9933e00.HTM (acedido em 28 Março, 2014).

FELIX-FILHO, José (1994) - Integração e concretização de Medidas Mitigadoras no Projeto Rodoviário. Seminário sobre a Avaliação de Impacte Ambiental de Projetos Rodoviários. Espinho, Portugal. 16 a 19 de Março de 1994.

FELIX-FILHO, José (1994) - Método Simples de Previsão de Impactes na Qualidade da Água Associados às Águas de Escorrência de Estradas. Seminário sobre a Avaliação de Impacte Ambiental de Projetos Rodoviários. Espinho, Portugal. 16 a 19 de Março de 1994.

FELIX-FILHO, José (1995) - Controlo de Impactes Ambientais de obras de Engenharia Civil. Seminário Luso -Brasileiro de Geotécnica Ambiental. Lisboa, Portugal. 30 e 31 de Março de 1995. 
GASSER, Monique et al. (2004) - Autoroutes et aménagements. Presses Polytechniques et Universitaires Romandes. Lausane, $\mathrm{CH}, 327 \mathrm{p}$.

JOHNSTON, Kevin et al. (2001) - Using ArcGis ® Geostatistical Analyst (ESRI@). ESRI Press. Redland, California, USA, 300p. Disponível online no endereço url: http://dusk2.geo.orst.edu/gis/geostat_analyst.pdf. (acedido em 28 Março, 2014).

KELEAGETSE, Sewelo (2001) - Exploring the linkage of Environmental Impact Assessment and Geographic Information Systems: A Case Study of the Run Expressway, Morgantow, Monongalia County, West Virgínia. Tese de Mestrado em Geografia, West Virgínia University, USA, 95p. Disponível online no endereço url: http://wvuscholar.wvu.edu:1801/webclient/ DeliveryManager?pid=6102 (acedido em 28 Março, 2014).

LOOIJEN, Joan (2004) - Environmental Impact Assessment using GIS and MCE. The International Institute for Geo -Information Science and Earth Observation, Netherlands. Disponível online no endereço url: http://www2.hcmuaf.edu. vn/data/quoctuan/Environmental\%20Impact\%20Assesm ent.pdf. (acedido em 28 Março, 2014).

LOUREIRO, Henrique (2004) - Curso Avançado de Programação em Access com VBA. FCA - Editora de Informática, Lda. Lisboa, Portugal,336p.

MALCZEWSKI, Jacek (1999) - Gis and Multicriteria Decision Analysis. John Wiley \& Sons, Inc, USA, 408p.

MAYSTRE, Lucien. et al. (1994) - Méthodes multicritères ELECTRE. Press Polytechniques et Universitaires Romandes. Laussane, $\mathrm{CH}, 327 \mathrm{p}$.

MCCOY, Jill et al. (2002) - Using ArcGis ${ }^{\circledR}$ Spatial Analyst (ESRI@). ESRI Press, Redland, Califórnia,USA, 230p. Disponível online no endereço url: http:// www.web.pdx.edu/ emch/gis1/Using_ArcGIS_Spatial_Analyst.pdf (acedido em 28 Março, 2014)

MOLINES, Nathalie \& CHEVALLIER, Jean -Jacques (2002) - Système d' information géographique et analyse multicritère: une association novatrice au service du processus d' évaluation des grandes infrastructures linaires. Disponível online no endereço url: http://biblio.nantes.archi.fr/cgi -bin/koha/opac detail.pl?biblionumber=27051 (acedido em 28 Março,2014).

NINA, Nuno (1999) - Visual Basic 6, Curso Completo. FCA- Editora de Informática, Lda. Lisboa, Portugal, 1104p.

ORMSBY, Tim. et al. (2004) - Getting to Know ArcGis® desktop, update for ArcGis 9.0. ESRI Press. Redland, California, EUA,535p.

PAMANIKABUD, Pichai \& TANSATCHA, Marupong (2001) - "Geographical information system for traffic noise analysis and forecasting with the appearance of barriers". Environmental Modeling \& Software Journal, Disponível online no endereço url: http://www.sciencedirect.com/science/article/pii/ 
S1364815203000975. (acedido em 28 Março, 2014).

PIMENTA, Maria (1998) - Directrizes para a Aplicação da Equação Universal de Perda dos Solos em SIG. Factor de Cultura C e Factor de Erodibilidade do Solo K. Institui da Água (INAG), Direção de Serviços de Recursos Hídricos (DSRH), Lisboa, 12p.

PINHO, Paulo (1997) - Apontamentos das Aulas de Gestão Ambiental. Curso de Mestrado em Engenharia Urbana, 97 -99. Universidade de Coimbra, Portugal.

RODRIGUES-BACHILLER, Agustin \& GLASSON, John. (2004) - Expert Systems and Geographical Information Systems for Impact Assessment. Taylor and Francis, Inc. London, UK, 408p.

RODRIGUES, Pimenta et al. (1998) - Programação em C++, Conceitos básicos e algoritmos. FCA - Editora de Informática, Lda. Lisboa, Portugal, 478p.

TAM, Chi Ming et al. (2002) - ELECTRE III in evaluating performance of construction plants. University of Hong Kong, Hong Kong. Disponível online no endereço url: http://www.emeraldinsight.com/journals.htm?articleid=1577590 (acedido em 28 Março, 2014).

TOMÁS, Pedro (2003) - Erosão Hídrica do Solo em Pequenas Bacias Hidrográficas. Aplicação da Equação Universal de Perda de Solo. Disponível online no endereço url:https://fenix.tecnico.ulisboa.pt/downloadFile/3779571248015/ ErosaoPeqBacias .pdf (acedido em 28 Março, 2014).

VLADO, V. (2002) - Knowledge Based GIS for Site Suitability. Disponível online no endereço url: http://proceedings.esri.com/library/userconf/proc02/ pap1185/ p1185.htm (acedido em 28 Março, 2014).

ZEILER, Michael (1999) - Modeling Our World. The Esri® Guide to Geodatabse Design. Environmental Systems Research Institute, Inc. Redlands,Califórnia, USA, 199 p. 
Série Documentos

Imprensa da Universidade de Coimbra

Coimbra University Press

2015

- U M

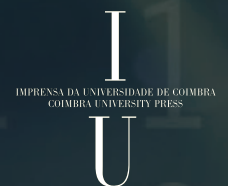

